\title{
Simulations, Games and Role-play
}

1 Introduction 2

2 Why use simulations, games and role-play? 3

3 When to use SGRP 4

4 Case studies in how to use SGRP 5

4.1 Case study 1: The Virtual Economy 5

4.2 Case study 2: The International Trade Game 9

$\begin{array}{ll}\text { 4.3 Case study 3: The Press Briefing } & 16\end{array}$

$5 \quad$ Devising your own SGRP: some points for consideration 21

$\begin{array}{lll}5.1 & \text { Devising clear guidelines } & 21\end{array}$

$\begin{array}{lll}5.2 & \text { The importance of debriefing } & 21\end{array}$

$\begin{array}{lll}5.3 & \text { Realism } & 22\end{array}$

$\begin{array}{lll}5.4 & \text { Assessment } & 22\end{array}$

5.5 Role-taking and role-playing 22

5.6 Using scripted role-play 23

6 New technology and SGRP 24

7 Conclusions $\quad 25$

$8 \quad$ Suggested reading $\quad 25$

$\begin{array}{ll}\text { References } & 26\end{array}$ 


\section{Introduction}

The use of games and simulations in economics is well established, with a well-developed body of literature to support their use in the teaching environment (see the section 8 for a list of key sources). Role-play, as an educational approach, is often referred to in the same context as games and simulations. However, the use of role-plays in teaching has received far less attention. Collectively, simulations, games and role-play (SGRP) provide students with some form of imaginary or real world within which to act out a given situation. Beyond this, however, each is quite distinct.

The aim of a simulation is to deepen students' conceptual understanding by working within, and reflecting upon, a representation of a real environment. For example, simulations of the macroeconomy may be used to train economists by requiring them to devise economic strategies to achieve policy objectives. The dynamic of a simulation may be competitive, whereby students are encouraged either to outperform other students or to achieve a high rating according to criteria set by the simulation. In these cases the simulation is also a game. However, students might also be encouraged to explore a simulation, to investigate its behaviour and discover its assumptions. For example, they might be asked to set their own criteria for 'successful performance' within a simulation and then to investigate how best to achieve that performance. In most cases, it is the way in which a simulation is used that determines whether or not it is effectively a game. This choice has important implications for the way in which a simulation may contribute to learning.

Games may be distinguished from other forms of simulation by the rules that dictate what it means to 'win' the game and the sense of competition they engender. Games tend to have winners and losers. For example, a typical form of business game requires students to compete with others in buying and selling shares on the stock market. Such games operate with clear rules for the process and timing of share trading, and they encourage students to compete on the basis of achieving the highest level of profit through their trading.

Simulations become role-plays when the student is expected to act as they imagine appropriate to a given role. For example, they might be asked to act as a stockbroker in a share-dealing simulation or as the Chancellor of the Exchequer in managing the economy. The opportunity for the student to act out the role is bounded by the rules of the simulation and the degree to which the simulation is constructed as a game. As games usually require tight rules, role-plays are likely to give more scope for the student to exercise their own interpretation of the role when the simulation is not constructed as a game.

This chapter explores the world of SGRP. Sections 2 and 3 examine basic principles in using SGRP in teaching. Following a review of the major strengths and weaknesses of using SGRP in teaching and learning in section 2, section 3 examines the rationale for using SGRP at different points in a programme of teaching. Much of the chapter is taken up with three case studies of practice presented in section 4 . These case studies have been chosen because they are easily available and can be adapted for different circumstances. Section 5 reviews some of the key issues to be considered in designing SGRP and section 6 examines the growing impact of new technology on using SGRP in higher education. The chapter ends with brief conclusions and suggestions for further reading. 


\section{Why use simulations, games and role-play?}

In this section we will review the main arguments both for and against the use of SGRP as a teaching and learning strategy. Although, in many respects, simulations, games and role-play offer distinct strengths and weaknesses, in a majority of cases arguments both for and against their use are the same. This section will therefore evaluate SGRP in general terms, making specific reference to a particular approach only where necessary.

Supporters of the use of SGRP as a teaching strategy are frequently found to argue that its greatest virtue is that students are encouraged to reflect on their knowledge and draw together the various dimensions of their course of study (Alden, 1999; Oberhofer, 1999). It is, however, also recognised (Alden, 1999) that there is always a threat of simplification, where students fail to draw upon or make optimum use of the knowledge they have been taught. The issue for the tutor is whether sufficient safeguards can be initiated to minimise such simplification, such as the construction of clear guidance notes (see below).

In addition, SGRP often require the tutor to relinquish some control over the process and outcomes of learning. Are students reflecting upon their knowledge in the most effective way? Francis and Byrne (1999) suggest that this drawback in using SGRP might in fact be turned into an advantage. They argue that one of the greatest benefits they found when using SGRP in their teaching programme was that it helped reveal 'sticking points in student understanding' ( $p$. 209), in the light of which they were able to rectify the design of their course.

As well as encouraging students to reflect upon their theoretical understanding of economic concepts and arguments, SGRP is an excellent approach by which to develop in students a greater appreciation of role and responsibility. As a teaching method, SGRP can encourage students to empathise with the position and feelings of others and to look beyond their immediate assumptions and expectations. As Freeman and Capper (1998) remark following an evaluation of their Web-based simulation role-play, students 'achieved a deeper understanding of their own views and those of others' (p. 12). When evaluating issues of role and responsibility, it is important for the tutor to recognise that roles might also be distorted and stereotyped, and might in certain cases fail to reflect an accurate perception of those whom it might claim to represent. In such cases, careful debriefing is essential.

Many studies (Francis and Byrne, 1999; Oberhofer, 1999) have claimed that SGRP, especially when group based, have contributed to a positive change in classroom dynamics. It has been suggested (Francis and Byrne, 1999) that they help break down barriers and stimulates a greater level of long-term interactivity between students. Problems, however, might arise if students fail to take the SGRP seriously, seeing it merely as a break from 'real' teaching. Oberhofer (1999) remarks upon this issue when devising a history of economic thought class based totally upon role-play. He notes that when devising the course he had to consider not only whether those studying the course would have the ability to make the role-play work, but also whether they would be willing to take on the responsibility such a course would demand and fully 'engage in the enterprise' (p. 113).

Supporters of SGRP (Neral and Ray, 1995; Lowry, 1999) claim that such an approach to teaching and learning can give life and relevance to academically descriptive material. Remote theoretical concepts can be given life by placing them in a situation with which students are familiar. For example, understanding the workings of the market might be far more effectively 
relayed to students through a simple game rather than a theoretical discussion of the principles of demand and supply.

Neral and Ray (1995), in discussing the merits of teaching costs and production via a game, remark that 'many of the students in our introductory courses have difficulty in dealing with the high level of abstraction that permeates economic theory, [and] it can be extremely helpful to provide these students with concrete examples of the phenomena that the theories attempt to describe' (p. 170). They dismiss simply giving real-world examples as illustration, claiming that students have different experiences and many will be unable to relate to the examples given. However, the use of classroom games, they claim, 'ensures that all students have at least some level of common experience upon which to base their understanding of the relevant theory, [and second] it actively involves the student in the learning process' (p. 170).

As well as knowledge and roles, SGRP can contribute positively to the development of key transferable skills, particularly in terms of communication and social skills. Depending upon the organisation of the activity, it may be possible to develop skills in recognising and presenting arguments, presenting to an audience and working collaboratively in a group. The literature on SGRP (Francis and Byrne, 1999; Alden, 1999; Gremmen and Potters, 1997) suggests that the typical use of SGRP involves group work, and as such draws upon its relative strengths and weaknesses. Most SGRP, such as those highlighted in the case studies in section 4, require students to solve problems through analysis, synthesis and evaluation: all high level skills.

The final issue to raise in this section concerns the development and running of SGRP. Preparing, running and debriefing SGRP often requires more time and effort from the tutor than a traditional approach to teaching. Oberhofer (1999) and Lowry (1999) both remark on the high start-up costs that SGRP can sometimes generate. The issue that requires resolving is whether SGRP improve learning sufficiently to justify this additional effort. Evidence suggests (Gremmen and Potters, 1997; Rodgers, 1996) that where evaluations have been considered in this respect, the gains from using SGRP have been found to justify the costs that such teaching methods often entail.

\section{When to use SGRP}

Simulations, games and role-play may be used to serve different purposes at different points in a course. This section briefly reviews reasons for using SGRP in the beginning, middle and final stages of a programme of teaching. Given the similarities and overlap between SGRP, I have assumed they will perform similar functions at the various stages of a course of study. Admittedly, games are more likely to be effective as icebreakers than role-play, and simulations and role-play are more likely to be effective teaching strategies when reviewing a programme of study. However, the key issue as to when to use SGRP is the degree to which prior student knowledge is crucial to its success. This will largely determine when SGRP ought to be used.

SGRP create learning environments in which students talk to each other, solve problems and work collaboratively. Francis and Byrne (1999) found that one of the greatest benefits from conducting a role-play exercise amongst undergraduate astronomy and physics students was 
that it changed classroom dynamics into a 'noticeably more interactive and friendly' environment (p. 209). They felt that the role-play they used broke down barriers. Consequently, SGRP may be used as icebreakers at the start of a course and may be used to develop a culture in which students learn from each other. For this reason, they might be regarded as contributing to the development of an effective learning community. The International Trade Game (section 4.2 ) is an excellent example of a game that can be used to perform such a task. The game introduces some key principles of trade theory and policy, focusing especially on issues of efficiency and equity, and prompting questions about the fairness of the trading environment.

SGRP may also be used within the teaching of a module to deepen understanding by placing theoretically remote ideas in real-world situations. However, such potential gains need to be balanced against any additional tutor time that may be required in implementing SGRP (Gremmen and Potters, 1997) and the prior knowledge that students will require. According to Rodgers (1996), this is particularly important for role-plays, for which students will require 'background information and appropriate economic tools to play their roles effectively' (p. 219). The importance of background knowledge explains why tutors may regard the end of a course or theme as the most appropriate point at which to use SGRP. At this time SGRP may be used to help students to pull ideas and concepts together, clarifying connections between different aspects of their study. This should help them to recognise the interconnected nature of economic ideas.

\section{Case studies in how to use SGRP}

The three case studies in this section have been selected to exemplify a simulation, a game and a role-play in current use. I have used the simulation and the game for a number of years, and their impact upon the teaching and learning process has been evaluated over a long period. The role-play is new. In this case study I will explain why and how I devised it, and what I hope it will deliver within my teaching programme.

\subsection{Case study 1: The Virtual Economy ${ }^{1}$}

\section{The simulation}

The Virtual Economy is a sophisticated online Web-based model of the UK economy with extensive supporting materials. It was developed jointly by the Institute for Fiscal Studies and the Biz/ed group at the University of Bristol with the support of the Nuffield Foundation. The model is based on the home of the UK Chancellor of the Exchequer. Many macroeconomic policy simulations have been devised as games. However, the Virtual Economy is not a game. It is designed to encourage students to explore the operation of a macroeconomic model and does not have the structure of 'rounds' and 'point scoring' typical of macroeconomic games. The simulation presents a virtual ' 11 Downing Street', which is split into five floors, and the 

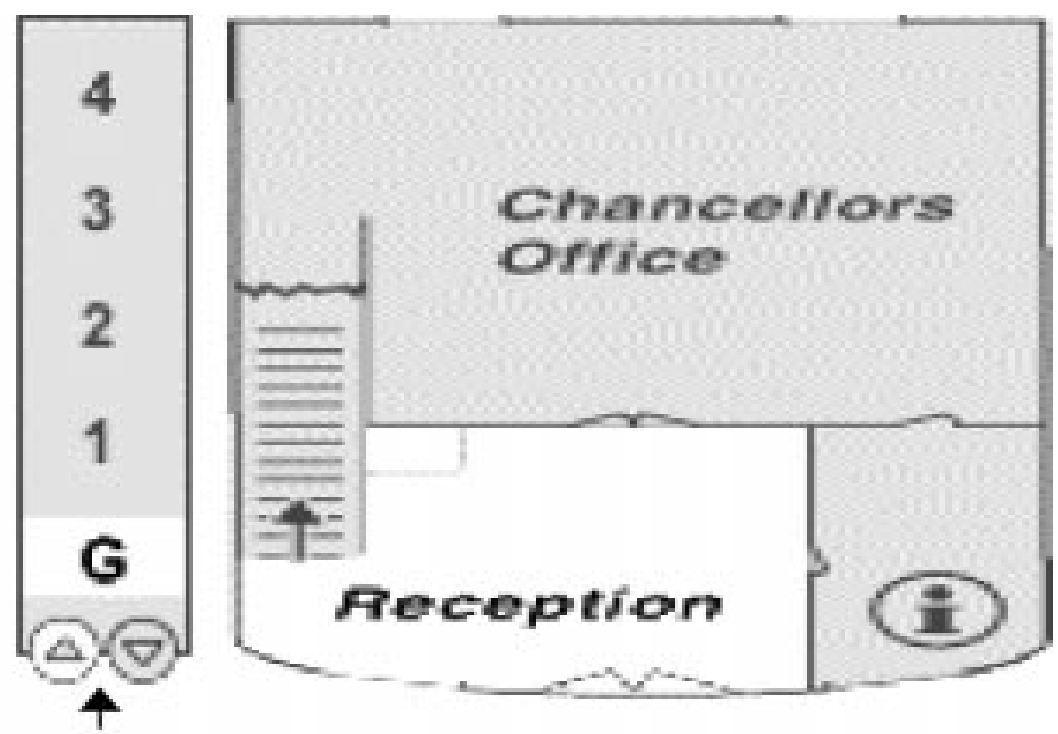

'Lift' to navigate

between floors

Ground floor - Chancellor's office with an introduction to the Virtual Economy and an information bureau with teacher's guide, student's guide and details of the model.

1 st floor - Case Studies - this floor has case studies about the impact of changes in the economy on people, business and governments.

2nd floor-Economic Policy - a whole floor dedicated to the different economic variables in the model. Here you'll find advice, explanations, worksheets and relevant economic theories about everything in the Virtual Economy.

3rd floor - Library - you can browse here for all sorts of help. There are details on famous economists, all types of economic theory and a full glossary of all terms in the Virtual Economy.

4th floor - The Model - on this floor is the model itself. Try changing anything you like and see the effect on the economy.

Figure Visual display from 'Virtual Economy'

navigation allows the user to jump from floor to floor. Each floor contains a number of virtual rooms that contain various resources. The home page lists the contents of each floor as shown in Figure 1.

The model of the UK economy at the heart of this package is similar to that used by the Treasury and the Bank of England to model the effects of policy changes. Students can see the macroeconomic and microeconomic impact of changes in various macroeconomic instruments. Analysis of microeconomic effects is prompted by the inclusion of several business case studies and family types (found on the first floor). The simulation calculates the impact of policy changes on each family type. Teacher's and student's guides are given on 'the ground floor' and these suggest various ways in which the package can be used.

The package contains various printable worksheets (on the second floor). All worksheets are designed to guide students' experimentation with the model. The teacher's guide suggests that

The materials could be used for self-paced study. Students could gradually work through sections researching relevant theories, doing worksheets and experimenting with different policies on the model. Lecturers may want to use the model for classroom experimentation. If 
there is an Internet connection, then it would be possible to use the model as a basis for discussion with classes. Students could suggest policies and try to predict the outcome of them. The policies can then be tried on the model to see how good their predictions were. Students could do this individually or in groups as well. Different groups could be set different targets, and they could see how easily they can meet them. This also should help to provide a basis for discussion. ${ }^{2}$

\section{Main learning outcomes}

The main subject learning outcomes from running the Virtual Economy simulation focus upon developing students' understanding of the macro economy, the interaction between the main macroeconomic variables and the ability of government, via economic management, to shape economic performance. With suitable focus, students can also learn about the relationship between business and the macro economy, and the impact that changes in the macro economy have upon families and wider issues of social welfare.

As well as such subject-related learning outcomes, the Virtual Economy simulation also develops other skills. For example, given the assignment brief for students at the University of the West of England (reviewed below), students are encouraged to spend time on refining presentation skills ( 20 per cent of the assignment mark is dedicated to such considerations). The simulation also helps develop higher-level cognitive skills such as analysis and evaluation, where students are asked to apply macroeconomic outcomes generated by the simulation to a business and its future performance. Depending upon the focus of the lecturer, the Virtual Economy simulation can be used in a number of ways, developing a wide range of learning outcomes.

\section{Using the Virtual Economy for assessment: an example from the University of the West of England}

The Virtual Economy was used as the basis for an assignment given to 900 first-year undergraduates at the University of the West of England. These students are studying for a 3year honours degree in business studies. They take six modules per year, and Economic Principles is compulsory as one of the six in the first year. The Virtual Economy assignment accounts for 40 per cent of the students' marks (the other 60 per cent being from an exam (50 per cent) and a test (10 per cent)).

The students first explore the model and the supporting information on their own. Following this they are asked to select two policy stances and a business that will be affected by those policies:

- The two policy stances must be chosen from four options - deflationary, reflationary, supplyside and redistributive - which are described on the first floor (http://www.bized.ac.uk/virtual/economy/studies/business/policies.htm).

- The business is chosen from five case studies also presented on floor 1 (http://www.bized.ac.uk/virtual/economy/studies/business/).

Students then move to the model and input changes consistent with the first policy approach (as directed by the selected policy approach). A summary of the results then appears, which can be transferred to a spreadsheet and printed out. The procedure is then repeated for the second policy approach.

After they have completed their investigation of the model, students are asked to write a report, reviewing the impact of their policy changes on their chosen business. They are asked to answer the following questions in their report: 
- What impact are the policy changes likely to have on the level of demand for the company's product? Why?

- What impact are the policy changes likely to have on the company's costs? Why?

- What impact are the policy changes likely to have on the company's profitability? Why?

- What impact are the policy changes likely to have on other aspects of the company's financial situation? Why? (In this area you might like to consider: the level of liquidity, the level of inventories, the level of bad debts, any income on investment, interest payments, etc.)

- What strategies could the firm adopt to counter the effects of the policies?

- Should they change their marketing strategy? If so, which aspects: their pricing strategy, their advertising, the nature of the product itself ...?

- What policies should they lobby the government to carry out?

The tutor evaluates the report according to the following criteria:

- structure (25 per cent);

- $\operatorname{argument}(25$ per cent);

- originality (10 per cent);

- style (10 per cent);

- presentation (20 per cent);

- sources (5 per cent);

- spelling, grammar, etc. (5 per cent).

\section{A review of using the Virtual Economy}

To use the simulation effectively, students need to look at the relevant information and to plan their analysis of this information. The tutor has to decide how much guidance to give to students in each of these tasks. There is a tension here between providing sufficient guidance to enable the exercise to run smoothly and giving students sufficient opportunity to develop their own ideas and to work independently. As a general rule, it is a good idea to make sure that the students are carefully guided through the available information. Less able students could very easily get lost in the sheer volume of material provided by the Virtual Economy. However, too much guidance on distinguishing between more and less relevant information and on planning the course of the investigation will deprive the students of the opportunity to work independently.

Independent learning can be encouraged by asking students to identify and articulate factors that they regard as relevant and to express lines of reasoning that they believe can account for the predictions provided by the model. Final-year students, who might be expected to possess a broad and reasonably deep understanding of economics, might be asked to construct their own policy framework, given the current state of the economy, and to evaluate the reasons for their policy choice and its outcomes. They might also be encouraged to construct and justify their own criteria for evaluating the outcomes for business.

First-year and less confident students will require more guidance, but a list of points that they might consider in their investigation should be sufficient. The quality of work produced by firstyear students has been very good. The average mark was above that awarded in previous years when a student's understanding of this topic was assessed through an essay without any use of the simulation. However, although the general standard of the assignments was good, there was a tendency for students to provide an insufficient theoretical basis for the arguments they advanced. We interpreted the general improvement in students' work as a reflection of the 
amount of time that students had devoted to their analysis. Students who worked harder on the review gained higher marks.

The author's current work in progress suggests that students who were familiar with the operation of the macro economy prior to running the Virtual Economy model felt that the module had helped deepen their understanding of the economy and its operation and performance. This may go some way to explain the higher standard of work achieved. It has also been suggested by this work that students' efforts in the Virtual Economy assignment reflected the fact that they found the assignment medium interesting, and subsequently were more engaged with their study.

Even for experienced markers, the assessment of students' reports proved difficult. Students approached their assignment in many different ways and this made it difficult to devise a mark scheme that adequately compared the quality of their work. The reliability problems were highlighted by early attempts at double marking prior to devising a marking scheme. In 10 per cent of cases, marks diverged by more than 15 per cent. Tutors then met to negotiate marks. Following these negotiations the assessment team met to compile a set of marking criteria. These criteria were made available to students alongside their marked scripts and comments on the reasons for the mark awarded to their script. Even though this process was time consuming, it was necessary to ensure reliability and transparency in the assessment. Even using the final assessment criteria, markers took an average of 30 minutes to mark each script. It is difficult to judge whether marking will continue to take this long once tutors are more experienced with this format of assessment and the criteria being employed.

Prior to using the Virtual Economy assignment, we had anticipated that students would prefer assessment in the form of an essay. To our surprise, the reaction of students to the new assignment was very positive. Many students commented that, although they found the assignment very challenging, they also found it very rewarding. A number of students commented that they needed access to fewer books to complete the assignment and that this created less pressure on library resources.

In the second year of using the assignment, we introduced several changes. First, the percentage of coursework marks devoted to the assignment was increased from 30 to 40 per cent. We felt that students spent many hours investigating and writing the assignment and that this should be reflected in the weighting of the assignment. Second, we replaced a second element of coursework with a multiple-choice test in order to reduce the marking load on staff. Third, the macroeconomic section of the course was linked more closely to the themes of the Virtual Economy assignment, in order to link the policy aspects of the assignment more closely to the theory presented in lectures. In this way, we aimed to improve the theoretical underpinning of the policy arguments that the students offered in their assignments.

The course team who developed and marked this assignment have found it a rewarding experience, and the evidence so far suggests that students appreciate its value. It is felt not only that the assignment develops skills in it own right, but that it enables students to build and articulate skills that they have been encouraged to develop, such as analysis and evaluation., as well as key skills in presentation.

\subsection{Case study 2: The International Trade Game3}

\section{The game}

This game is a version of the International Trade Game developed by the Third World development charity Action Aid. It has been amended to be suitable for students beginning a course in economics, economic development or international trade, although it could be used with students studying related subjects. 
Students are divided into teams, each of which acts as a separate 'country', with between four and ten students in each team. There are five or six countries in a game. Countries compete against each other to 'manufacture' paper shapes (circles, triangles, rectangles, etc.) and sell them to an international commodity market trader at posted prices, which vary with supply and demand. The objective for each country is to make as much money as possible.

There are three types of country in a game:

- two rich industrialised countries;

- one or two middle-income countries;

- two low-income countries.

Students are not told this; they find out as they play the game.

The game requires a large flat room, with loose tables and chairs. Each game can be played with between 20 and 60 students and, with sufficient space, two games can be played simultaneously. Only one lecturer is required as game leader even if more than one game is being played, but one additional person is required to act as a 'commodity trader' in each game. This person could be a student. It is also useful to have one or two 'observers' for each game. These too can be students. Experienced game leaders could handle up to four simultaneous games (i.e. up to 240 students) if the room is appropriate.

The game takes between 45 and 90 minutes to play. This is followed by scoring, reporting by students and adjudication by the lecturer, who will probably want to draw various economic lessons from the game. This all lasts a further $20-45$ minutes. Students find the game enjoyable and rapidly enter into its spirit.

The game is very simple to set up. It needs no computing facilities and uses only very basic equipment, such as scissors, pencils, rulers and paper. All the necessary instructions can be given to the participants within 2 minutes. Preparing the materials for the game usually takes about 20-30 minutes and, except for paper, all the materials used for the game can be reused. The resources required are shown in Figures 2-5.

The resources for each type of country are placed in envelopes so that they can be allocated quickly to each team at the beginning of the game. The large templates (see Figure 4) should be displayed in a location that is easily visible but out of reach of students. A recommended room layout is shown in Figure 6. If you are playing two or more games (or 'worlds') simultaneously, you will need to separate them with a line of tables or some other barrier, as students must not cross from one game to another.

The game requires minimal, but clear instructions immediately that students have entered the room (Figure 7). The dynamic of the game requires that there is no preamble explaining the purpose of the game and certainly no summary from the lecturer explaining what the game is supposed to illustrate. It is important for the students to work out what they should do. Once the instructions in Figure 7 are understood, it is time for the lecturer to tell students how long they have to play the game (usually 45 minutes) and to announce the start of manufacturing.

At the beginning of the game there will be a lot of confusion and students will have many questions, such as 'Where can I get scissors?', 'Why have we only got paper?', 'Can we buy things off other countries?', 'Can we combine with other countries?', 'Can we have a loan?' Resist all temptation to answer these questions. Just repeat what you said at the beginning. After a minute or two they should begin moving around the room and trading, but the initiative should come from them, not you. The rich countries (A1 and A2) will probably begin making shapes, as they have all the materials and equipment that they need, but they will soon run out of raw materials and will probably try to buy some paper from other groups.

Use the observers to report back to you on what is going on. This will help to give you information for the debrief session at the end. For example, get them to find out what is 


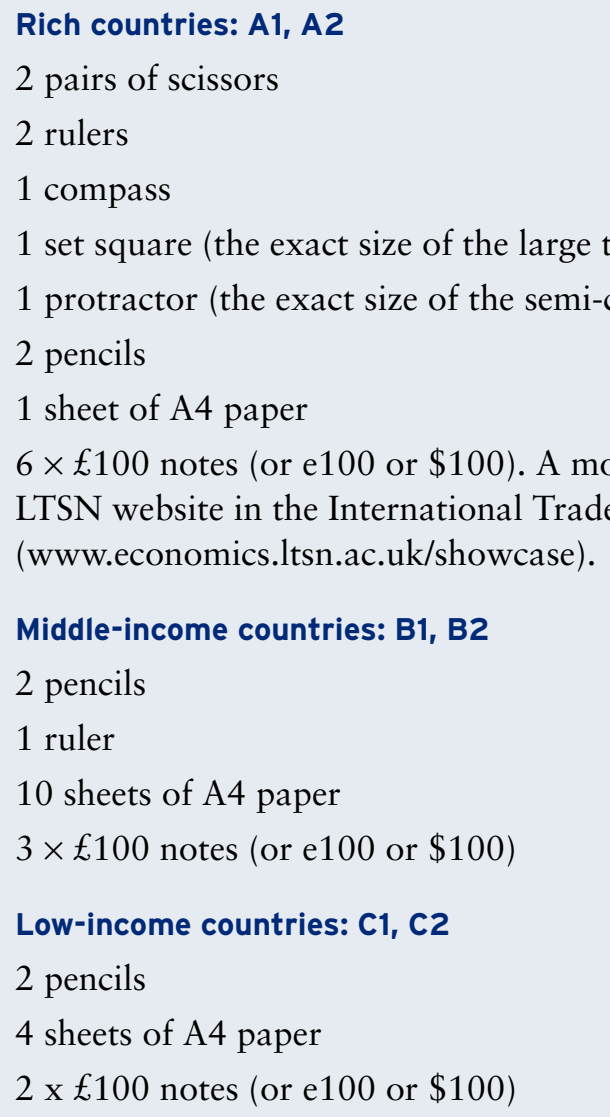

\section{Figure 2 Resources for each type of country}

Template of shapes with their prices (see Figure 4)

Banknotes: $30 @ £ 50 ; 60 @ £ 100 ; 20 @ £ 500 ; 40 @ £ 1000$

Pencil and rubber for marking changes to the prices of shapes

Large envelope for keeping completed shapes 'secure'

\section{Figure 3 Resources for commodity trader}

happening to the scissors - the one crucial implement that has to be used for all shapes and is possessed initially by only two countries. Do the rich countries form a scissors cartel? Do they sell one pair to another country; or do they hire them out?

Observers should watch how groups negotiate the prices of paper and other materials. They should note the formation and operation of any alliances and deals and any cheating that takes place. Observers should also report to you any malpractice, such as stealing other countries' paper, implements or shapes. It is up to you to decide whether you should ignore the problem, thereby encouraging countries to do their own policing, or whether you should impose a punishment, such as suspending them from making shapes for 5 minutes, confiscating certain materials or fining them.

The trader must be careful in measuring the shapes and reject any that have not been cut out. Alternatively, if they have been torn carefully against a ruler, or are only slightly too large or small, a reduced price could be given. You could leave this to the trader to decide, or you could agree a policy in advance. The trader must keep a close eye on the money to prevent students stealing it, preferably keeping it out of their reach. Shapes that have been sold should be put into an envelope or box, again out of reach of students. 


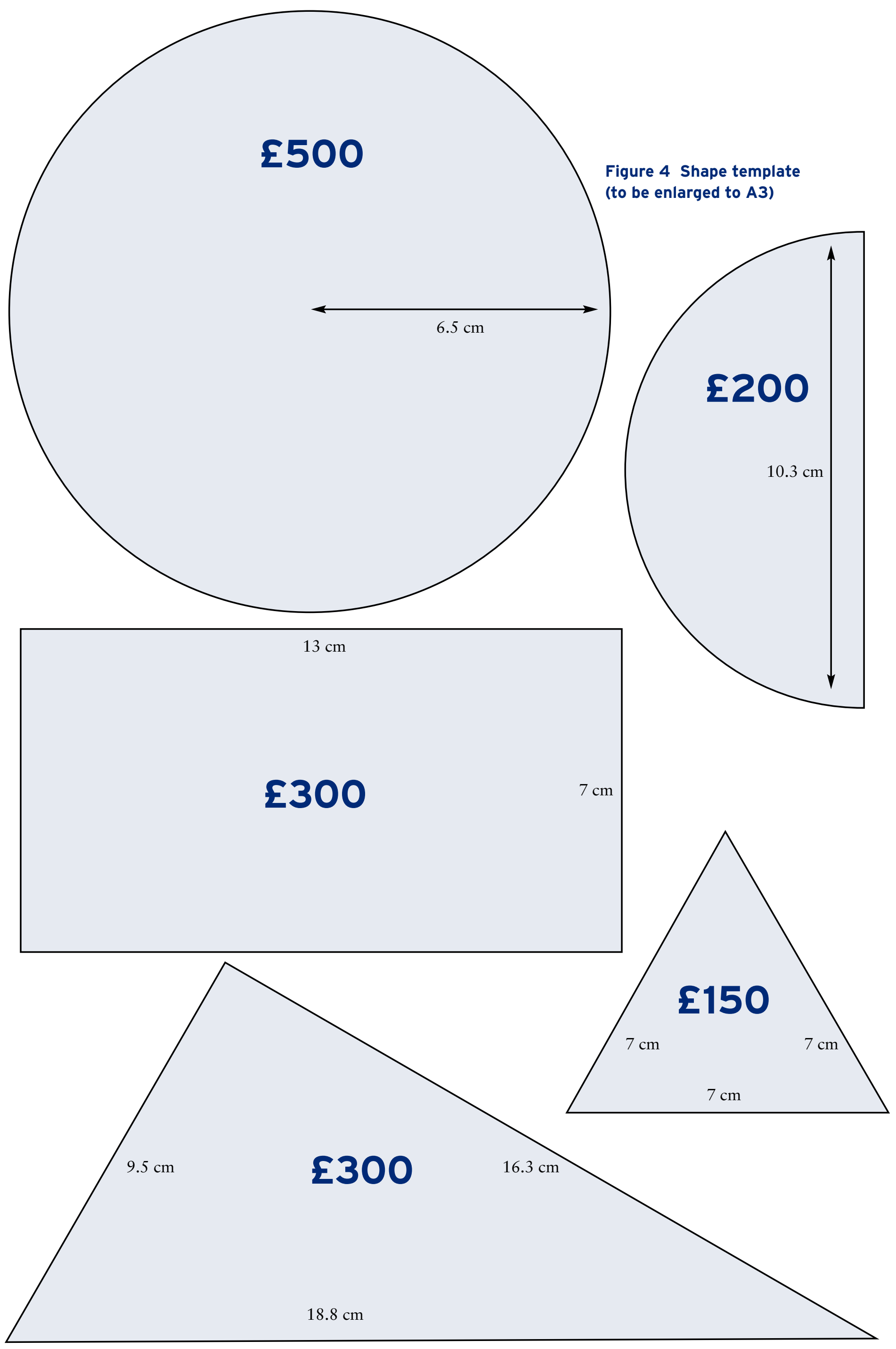


Two enlarged copies of the shape template (Figure 4) with opening prices. (These are to stick on the wall so that the players can see the required shapes and their sizes and values. These templates should have the measurements (in $\mathrm{cm}$ ) of each of the shapes.)

Whistle

6 small coloured sticky shapes per game

10 sheets of A4 paper per game

Pencil sharpener

Rubber

Figure 5 Resources for the game leader

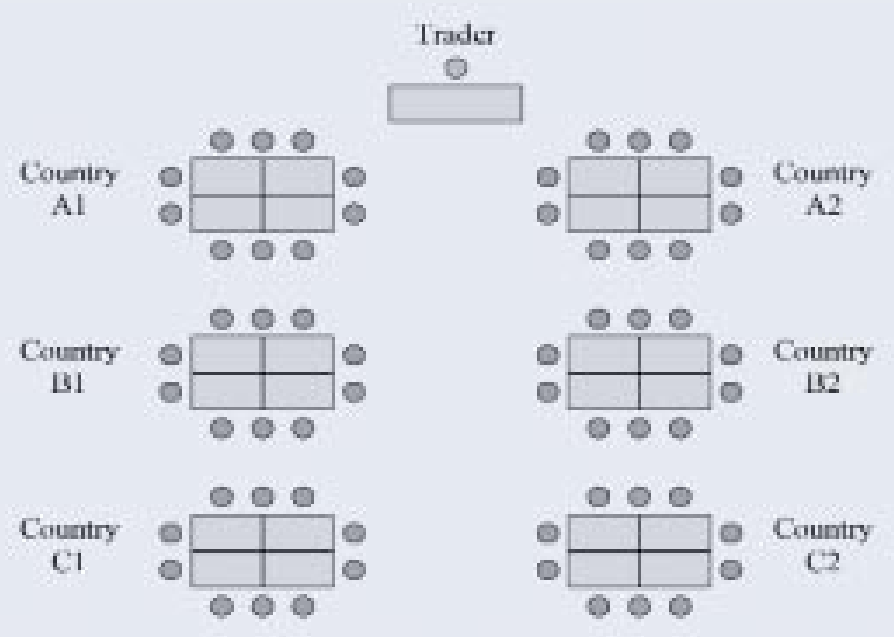

Figure 6 Room layout

Tell the students to leave all bags and any equipment (e.g. paper or pens) at the front and then to sit themselves around the clusters of tables (see Figure 6).

Distribute the envelopes to each of the countries.

Give the following instructions about the game:

Each of the groups is a team and represents a country. The objective for each country is to make as much money for itself as possible by using the materials in the envelope. No other materials can be used. Use the materials to manufacture paper shapes. You can choose to make any of the shapes shown on the diagrams on the wall.

All shapes must be cut with clean, sharp edges using scissors and must be of the exact size specified on the diagrams. The shapes can then be sold in batches to the trader, who will check them for accuracy and exchange them for cash. Inaccurate shapes will be rejected. You can manufacture as many shapes as you like - the more you make, the richer you will become. You must not cut up your envelope!

You can move around the room (but must not cross into the neighbouring world(s), who are playing a parallel game).*

If you hear me whistle [demonstrate], you must immediately stop what you are doing and pay attention. If there is any dispute, I will settle it. My word is final! No physical force is to be used in the game.

"If applicable. 
Traders should not normally give loans, unless you want to build this in as a feature of the game, in which case you should decide in advance what interest rate to charge - probably a high rate, such as 50 per cent. If loans are allowed, the trader should keep a record of them. In such cases, it might be a good idea to allocate an assistant to the trader. It is easiest for loans not to be repaid, but at the end of the game, when money is totalled, the trader will simply announce how much has to be deducted (outstanding loan plus interest) from each team.

You will need to keep in regular contact with the trader. Find out which shapes are being sold in large quantities (probably the triangles and rectangles) and which are hardly being sold at all (probably the circles and the protractor-sized semi-circles). Then blow the whistle and announce that, owing to the forces of demand and supply, the prices of certain shapes have changed. You can choose how much to change the prices, but a dramatic change stimulates more interest and provides a stronger focus for later discussion. For example, when the students are debriefed after they have finished the game, it is easier to refer to the importance of price elasticity of demand and price elasticity of supply when the price changes have been dramatic. For similar reasons, it is better to change prices very infrequently. The price of particular shapes will also affect the value of particular tools. If circles go up in price, this will affect the demand for compasses. This relationship can be identified later in the debriefing.

Extra dimensions can be introduced into the game by simulating the emergence of new technology, new raw materials or new equipment. It is important to make sure that the observers are primed to focus upon the reactions of groups to each change. The debrief will depend heavily on the quality of the information they are able to provide.

The development of new technology can be simulated by giving about 8 coloured small sticky shapes to one of the low-income countries, without indicating the possible use of those shapes. The game leader then goes to one (or both) of the rich or middle-income countries and informs them that the value of a standard shape is trebled if it has a coloured shape attached to it and that one of the low-income countries possesses coloured shapes. This scenario could also simulate the discovery of raw materials in a developing country, which are then developed by a multinational corporation investing in the country and bringing its expertise and technology with it.

You could also increase the stock of capital by selling a further pair scissors by auction. This will need to be done relatively early on in the game and you will need to announce your intention 5 or 10 minutes before you do so. Although the poor countries would dearly like to buy a pair, one of the rich countries is more likely to be successful at the auction. It might then hire out the scissors to a poor country.

As the game progresses, paper will rapidly run out. Trade in paper is likely to take place, with the price of paper rising to meet its value in terms of the shapes that can be made from it. The game can be prolonged by introducing more paper (simulating the discovery of new raw materials). You can do this in two ways. First, you may give some to one or both of the lowincome countries. The second way is to sell more paper. A good way of doing this is to hold a paper auction, where you sell about 10 sheets, one at a time. Announce that in 5 minutes' time you will be holding an auction and ask for one representative from each country to attend. The two issues are:

- How will the price at the auction reflect the value of shapes that can be made from it?

- Will the bidders collude to drive down the price?

You can draw lessons from this in the debrief session at the end.

The students should be given a 5 -minute warning of when the game will end. There will probably be a flurry of activity as students rush to make shapes with their remaining paper and bring those shapes to the commodity trader. When the game ends, the game leader should ask all the students to return to their countries and to answer three questions: 
-What was in their envelopes when they opened them?

- What implements do they currently own?

- How much money do they have?

\section{Collating results and debriefing students}

A whiteboard or flip chart can be used to record the results. The answer to the first of the questions (what was in the envelopes?) is known and it is helpful if this information has already been recorded on the flip chart or whiteboard. The answers to the other two questions can be gathered quickly so that the groups can easily compare their experience with that of other groups.

It can be helpful to organise the debriefing into three stages:

Stage 1. Draw students' attention to similarities and differences between the results from different groups. Did the groups that started with the same resources perform in a similar way? How much of the difference between the groups was due to strategies pursued and how much to the initial endowment? It is also appropriate at this stage to pose questions that prompt students to describe how they felt about the game as it developed. For example, the tutor could ask students in the different types of country how they felt when they opened their envelopes. Some further suggestions for questions to ask in this first stage are presented in Figure 8.

Stage 2. The second stage consists of asking the students to indicate ways in which they believe the game simulates the real world and ways in which they believe it is unrealistic. The capacity for simulations to affect students' thinking depends a great deal on whether they believe that the world is reflected in the simulation. It is quite usual for some students to dismiss as unrealistic aspects of a simulation that the lecturer is hoping to use to illustrate a theoretical idea.

One of the strengths of this game is that the inherent inequality in resource endowment that gives the game its distinctive character is hard to contest as a reflection of the real world economy. Students are more likely to question the way in which the game simulates the opportunities that these endowments create for different countries and how those opportunities are exploited.

Stage 3. In the third stage of the debriefing, the tutor aims to help students to compare the way they have analysed their experience in the game with the insights derived from economic ideas and the evidence that economists have assembled. This part of the debrief should be focused on those ideas that have been selected in the desired learning outcomes for the activity. The debriefing naturally begins as a large discussion group led by the tutor. However, if this format

(To more successful countries) How did you achieve your success? What problems did you experience and what strategies did you use to overcome them?

(To less successful countries) What factors limited your success? What strategies did you pursue? Which strategies failed and why? Now that you have learned how to play the game, what would you do differently next time?

(To countries that formed alliances) Why did you form the alliance? How well did it work? What prevented it from breaking up?

Compare the strategies of successful A countries, which probably involved exploiting their clear advantage at the beginning of the game, with those of relatively successful B and C countries, which probably involved clever negotiation and perhaps combining with other countries.

Figure 8 Questions to pose in the first stage of the debriefing 


\section{The International Trade Game can be used to illustrate the following economic topics:}

- Specialisation and division of labour. How did teams divide up the tasks? Was it more efficient to have some students cutting out the shapes, while others queued to sell the shapes, while others negotiated, and others scouted around to see what other teams were doing and whether there were opportunities that could be of benefit.

- Opportunity cost. What was the cost in terms of lost time, value from shapes, lack of access to equipment, etc. of particular decisions?

- Supply and demand and the determination of price. Why did prices vary as they did in the game? What determines the magnitude of commodity price changes in the real world?

- Prices as signals and incentives. How did teams respond to price changes; how elastic was their supply and why? Did anticipated price changes affect the production of shapes or when they were taken to the trader?

- Derived demand and the price of inputs. How did the prices of shapes affect the price of various pieces of equipment or their rental value? Do the same principles apply to pencils (in relatively plentiful supply) and scissors (in relatively short supply)?

- Cartels and oligopolistic collusion. What cartels did form? What cartels could have formed, and how would they have affected the balance of advantage in the game?

- Game theory: strategy, bargaining, trust, etc. What incentives were there for sticking to agreements and for breaking them? How would the number of people in a team or the number of teams involved in an agreement affect the likelihood of sticking to or breaking an agreement? How did risk attitudes determine strategy?

- The law of comparative advantage. Why do countries specialise in particular products? How does this depend on their resources? How does it relate to opportunity cost?

- Terms of trade. What determines the relative price of shapes and how does this relate to resources? Can countries influence the price of shapes?

- World inequality. You could refer to the distribution of resources in the world and ownership patterns. What determines whether inequality is likely to increase or decrease over time?

- The importance of market power in international trade. What is the role of multinationals? How do they control markets? Is there anything that developing countries can do to create countervailing power?

- The importance of resources and technology in determining trade patterns. Certain equipment is best designed to produce certain shapes. You could show how control over this equipment affects the pattern of trade and can influence prices.

- Imperfect information and acting on expected prices. How do price expectations influence production and the timing of sales? On what basis are price expectations formed? Do people learn from experience?

- Risk and uncertainty. There are several aspects of the game which involve uncertainty. These include the likelihood of obtaining equipment, future prices, the outcome of the paper auction, the role of the coloured sticky shapes, the effects of negotiations between other countries on their behaviour, and whether and what punishment will be imposed by the leader for 'malpractice'.

- Bidding and auctions. What determines the price at auctions? What determines whether there will be any collusion between bidders and what would be the outcome of that collusion?

The game may also be used to illustrate a number of more general development issues, such as the powerlessness of poor countries. It gives participants the opportunity to experience various emotions concerned with production and trade in an unequal world: emotions such as envy, greed, frustration and the desire to escape poverty by any means. In so doing, it can help students to gain a greater empathy with development and trading issues. To that extent it encourages students to move away from a typical textbook account of the embedded ideas and prompts them to consider alternative motives that might prompt economic behaviour. 
is maintained for more than 10-15 minutes, some students will get restless and there will be pressure for the tutor to end the session.

Given that the debriefing represents the tutor's main opportunity to develop students' thinking, it is important to find ways of avoiding a short and rather low-level discussion. The debriefing session needs to be planned as carefully as the activity. Typically this will involve asking students to discuss a couple of questions and arguments (during stages 2 and 3) within their 'country' groups. In stage 3 , when the focus is on economic ideas and evidence, it can be useful to have a small piece of evidence for each group to consider before returning to the whole-group discussion.

\section{Learning outcomes}

The International Trade Game has a wide range of potential learning outcomes, and with suitable focus, especially during the process of debriefing, a number of economic topics might be identified and developed more fully. These topics range from elementary trade theory to issues of imperfect information and even debates surrounding international inequality and first and third world relations. A comprehensive list of these economic topics can be found in Figure 9.

As well as the subject-related learning outcomes listed in Figure 9, the International Trade Game helps develop a number of key skills. Group working and interacting with others are amongst the most significant. The process of negotiating is also a very strong element within this game.

\subsection{Case study 3: The Press Briefing}

The case study below outlines a role-play designed for first-year undergraduates undertaking a business studies degree. Students' reflection on the role-play is assessed within a module entitled Global Business Context. This module replaced a more traditional course in introductory economics and seeks to inform students about competitive aspects of the global environment for business. The module places a strong emphasis on understanding the motivation of stakeholders and the implications of their actions for business. It is straightforward to identify stakeholders in international trade: governments, businesses, consumers, workers in different countries, NGOs, etc., and contrasting viewpoints on the benefits of international trade are often presented in stark terms. For these reasons it was decided that a role-play would help students to investigate issues in international trade in an interesting way.

The detailed instructions given to students are presented in Figure 10. Students are asked to work in groups. Each group chooses one issue in international trade as their focus and the group as a whole is required to research that issue from the standpoint of a specified stakeholder. They are required to provide a press release and a press information pack and to make a presentation as if they were that stakeholder.

The role-play takes the form of a press conference, where the conference presentation must be given in role, and the relevant supporting materials must also reflect the presenting group's perspective. The press release provides an abstract of the group's position. It is to be given out at the time of the press conference and students are told that the media will base their choice of headline on the content of the press release. The press pack contains the detail, and offers an indepth analysis of the group's standpoint. Students are encouraged to use a variety of resources within the pack, including material written by the group, supporting articles from other sources, statistics, and suggestions of sources of further information (such as websites). Students are informed that the strength of the press pack is in how it adds to the relevance of the group's argument. The presentation, no longer than 15 minutes in length, needs to articulate the press briefing. As with the briefing and the press pack, the presentation must be in role. 


\section{Introduction}

I am sure most of you have at some point in your life seen a press conference on TV. Well, for this assignment you have the opportunity to give one. You will, in groups, be expected to consider an issue in international trade with each of you delivering a presentation to the rest of the group. The twist is that you will be expected to present to the rest of the group from the perspective of a given stakeholder, whose views may be fundamentally different from your own.

A detailed assignment brief is set out below, please read it very carefully.

\section{What is being assessed?}

This assignment consists of three assessed components.

- a press release $(10 \%)$;

- a press pack $(40 \%)$;

- a presentation $(50 \%)$.

The press release. The press release should take the form of a single side of A4, which is to be given out at the press briefing. The release should identify the main issues you support and the policies you propose, as well as giving the media a headline!

The press pack. The press pack should offer the reader an in-depth analysis of your views and standpoint. It should include a wide variety of resources, which you feel help to make your case. Such a press pack will include material written by the group, articles from other sources, statistics and research sources. The press pack should be well structured and organised. It should include no more than 2000 of your own words (articles, statistics and research sources are in addition to this). The key to a good press pack is relevance and how it adds to your argument.

The presentation. The presentation must be no longer than 15 minutes in length. In this time you will be expected to outline your position on your given issue and make a case for your policy suggestions. The presentation must be in PowerPoint (a laptop and data projector will be provided). The presentation you make must be in role. It is not expected that you will present a balanced argument, but an argument from a particular viewpoint, expressing particular concerns and offering particular policy suggestions based upon these concerns.

Additional: group diary. Together with the submission of the press pack, each group must present a group diary. This should include a list of all group members, and a list of their responsibilities in the group work. The diary should also include a schedule of all group meetings, who was in attendance, who was absent and why. The diary must be signed by all group members as recognition that its contents are accurate, and submitted along with the press pack.

\section{Groups}

Groups will be selected at random prior to your first meeting and will be no larger than five students. At your first meeting you will be given a Blackboard chat room password, unique to your group. This will enable you to keep in easy contact with one another throughout the assignment. You are advised at this first meeting to schedule meeting times, devise a work schedule and provisionally allocate work tasks. You might wish at this stage to appoint a team leader to oversee the group's efforts, and to ensure that the team is moving in the same direction and that deadlines are kept. Alternatively, you might have a more devolved group structure in which all group members supervise every one else. The choice is very much up to each group concerned. If you do adopt a group leader approach, this may well require some additional rewards come mark time (see below). You most also decide, as a group, what is likely to be the most effective strategy in completing this assignment. This will invariably involve some division of labour following the initial phase of information gathering. Remember, your group will be more effective if you work together as a team. The assignment is run to a very tight and short deadline. This is intentional. You are being put under pressure to turn the work around fast - a phenomenon that you will invariably experience throughout your working lives. You have in effect only 2 weeks from your allocation into groups to your presentation. It is crucial that you are well organised and have a clear focus as to who is going to do what and by what deadline.

Please note: it is the responsibility of students who fail to turn up in the week that groups are allocated to contact either me or their workshop tutor to discover who their group is, and then to contact their group. Failure to do so will result in a zero mark, unless extenuating circumstances can be proven. One final point regarding group work: in your group you must respect all group members, and treat others as you expect to be treated yourself. Threatening behaviour of any sort will not be tolerated. 
Topics

There are six topic areas identified that are currently big issues in international trade. Each topic area must be considered from the perspective identified.

- Free trade and the environment: from the perspective of an environmental pressure group, such as Greenpeace.

- Child labour: from the perspective of a pressure group advocating its abolition, such as Save the Children.

- Genetically modified food: from the perspective of the EU.

- Trade-related intellectual property (Trip's): from the perspective of a lobby group representing the interests of western business, such as the pharmaceutical industry.

- Bananas: from the perspective of an African, Pacific and Caribbean (ACP) banana producer country, such as the Windward Islands.

- Trade and less developed economies: from the perspective of the World Trade Organization (WTO).

On Blackboard there will be a discussion room set up for each topic. You are strongly advised to visit and contribute to the ongoing debates. This would be an excellent forum for exploring issues surrounding the role-play element of this assignment. What values and views would inform a perspective from Greenpeace, or the EU? How does this fit with your understanding?

\section{Marking scheme}

The following marking scheme should be considered when completing this work.

The press release

Clarity and organisation $\quad 50 \%$

Headline potential $\quad 50 \%$

The press pack

Content

$40 \%$

Organisation $\quad 20 \%$

Presentation 20\%

Resources used and sources discovered $\quad 20 \%$

The presentation

Use of PowerPoint (visual) $\quad 30 \%$

Clarity of presentation including

content/organisation and communication $\quad 40 \%$

Role-play $\quad 30 \%$

\section{Marking and mark allocation}

At the end of this assignment, each group of students will receive a pool of marks. The pool of marks will be derived by totalling the marks from the three assessment elements of the assignment: press release, press pack and presentation. This total mark will then be multiplied by the number of group members. It will then be the group's decision to allocate such marks amongst group members as they see fit. The allocation of marks should reflect effort and the volume of work done. The allocation of marks must be confirmed to your group tutor within 1 week of the assignment pool mark being returned.

Failure to agree on a mark allocation will involve a process of arbitration by other students in the class. In the event of failing to reach an agreement after such arbitration, then marks will be allocated in the final instance by me. Hopefully this will not be necessary.

One point of clarification on deriving the group's pool mark: if the group has five members, but one does not attend, then the group will be classified as having only four members. You will only be able to claim marks for the number of members that actually took part in the group work.

Figure 10 Instructions to students on the Press Briefing role-play (continued) 
Student feedback will take two forms:

- in the tutor's written comments regarding the press release, presentation and press pack;

- a meeting of each group with their course tutor to discuss the issues that the assignment raised both in content and in conduct. This will help inform future years of this assignment.

\section{Learning outcomes}

The learning outcomes from this assignment are as much skills based as subject based. Students will be expected to analyse and evaluate a current issue in international trade, and identify alternative viewpoints regarding the nature of the issue and its potential resolution. They will be expected to identify the difficulties in resolving trade issues and how the political nature of international trade shapes economic arguments. Given that the cohort sitting this assignment are business studies students, a further element that this work will develop is the relationship and interaction between business and other stakeholder groups.

This assignment also offers the opportunity to develop a wide range of skills: group work and interaction, information retrieval and analysis, and presentational skills. The presentation skills include the use of PowerPoint, which is mandatory for the group presentation.

The assignment also attempts to promote independent learning and encourages students to take personal responsibility for and control of their own learning. With the support of a Blackboard virtual learning environment, each group has its own chat room, and there are discussion boards for all the topic areas.

\section{Future review}

The reasons for selecting role-play as a teaching strategy is that it gives the student an understanding and appreciation of alternatives. It will hopefully encourage students to reflect on their own views and, as a result, to understand more fully the position of others. Many of the arguments surrounding the issues that the students are asked to investigate have a moral or ethical dimension. This is far more likely to be understood if the student is forced to evaluate such an issue from a distinct point of view, as students will be forced to look beyond their immediate assumptions and expectations.

In order to maintain a measure of control over student learning, the confined nature of presentation and the specification that the press pack is focused on a distinct point of view should prevent students from deviating too far from the main focus of the assignment brief. It should be anticipated that more problems are likely to arise from group working and mark allocation than from the subject matter and its approach.

A full review of the assignment will be conducted at the end of 2003. 


\section{Devising your own SGRP: some points for consideration}

This section provides guidance for the design of simulations, games and role-plays in economics. Six key issues are introduced and discussed. The first four points are relevant to simulations, games and role-plays, whilst the last two points focus particularly on role-plays.

\subsection{Devising clear guidelines}

Clear guidelines are crucial to successful SGRP. If students are to learn independently, they must feel secure and certain in what they are being asked to do. The guidelines should certainly describe the main stages in the assignment and the criteria that will be used in assessment. The assignment briefs for the Virtual Economy and International Trade case studies illustrate the type of guidance that is required. Briefing guidelines are even more important for role-play than for games and simulations. This is because the tutor relinquishes more control in role-plays and it is important that students are able to work within a structure that generates a worthwhile experience for learning. Guidance notes for a role-play might take the form of outlining a character profile or identifying key aspects of knowledge that the role-player needs to consider in role. The detail included in the guidance notes may be varied according to students' prior attainment and skills, and their familiarity with this way of working.

\subsection{The importance of debriefing}

The process of debriefing students is crucial for ensuring its success. It allows the tutor and the student to reflect upon what has taken place, analysing the consequences of actions and the quality of arguments. It is also an opportunity for the tutor to correct errors, probe simplifications and expose assumptions. Consequently, debriefing is an essential part of the process of consolidating new knowledge and deepening understanding. Without it, students might walk away uncertain of the lessons they have learned. Debriefing frequently takes far longer than expected and needs to be carefully planned (as in case study 2). As a general rule, it is advisable to plan to spend 30 minutes debriefing for an hour's activity.

Debriefing begins with helping the students to articulate their perceptions of their experience during the SGRP. This provides a basis for helping them to analyse those perceptions, looking for similarities and differences, causation and argument. Only in the final stages of the debriefing are students ready to examine how their interpretation of their experience can be related to standard reasoning in economic theory. This approach to developing students' thinking reverses the traditional order of 'present theory and then follow up with applications of the theory to practice'. A rationale for teaching economics in this way is presented in McCormick et al. (1994). It can also be helpful to think of this approach to debriefing in the terms used by theorists of 'experiential learning' (e.g. Kolb and Allen, 1984). Students are also more likely to develop a considered and reflective evaluation if they write up their experience, either as a formative exercise or as part of a summative assessment process. 


\subsection{Realism}

If students regard a simulation as 'unrealistic', they are unlikely to regard its predictions as relevant to their understanding of the real world. In developing this argument, Bartlett and Amsler (1979) suggest that to be considered realistic a simulation must first be realistic in appearance. As Lowry (1999) argues, a successful SGRP depends upon 'Creating a realistic setting [which] changes the mood of the class and allows students to feel more comfortable adopting a role' (p. 125). Bartlett and Amsler (1979) also argue that a simulation must be realistic in its internal process - that is, it must imitate how the real world works in practice and produce realistic outcomes.

This poses an inherent problem in using simulations in teaching and learning. If the objective of teaching is to help students to recognise that the current way they interpret the world is inadequate, then teaching must present students with ways of thinking about the world that are different from the way they currently think. If this objective is pursued through a simulation, the simulation must present a model that is inconsistent with students' current thinking and there is a danger that students will dismiss the new model as unrealistic (Davies, 1994).

\subsection{Assessment}

The case studies in this chapter illustrate ways in which SGRP can be used in assessment. A key principle followed in these case studies is that the assessment focuses on students' reflection on their experience rather than on their performance in the simulation, game or role-play. For example, in the Virtual Economy simulation, students are asked to reflect upon the problems facing the Chancellor of the Exchequer. In answering this question, students are drawing upon their experience with the simulation, but they are not limited by their success in achieving particular outcomes in the simulation. Students' learning through a role-play might be assessed by asking them to identify what they believe they have learned from their experience in the roleplay.

When roles are more controlled, a wider range of assessment strategies become possible. This is exemplified in case study 3, where the role-play does not involve participating in a debate, but using the role to provide a structure for analysing a problem. When this approach is adopted, it is also useful to ask students to provide a critique of the way they have acted out the role. Students' ability to step out of role in their analysis is important to the development of their understanding of the subject.

\subsection{Role-taking and role-playing}

In role-plays, students attempt to increase their understanding of circumstances and roles that are beyond their immediate experience. However, the capacity of a student to enter into these new circumstances in a way that generates a useful stimulus for learning depends on the relevance of their prior knowledge and experience. Role-plays are much more likely to be successful if they place students in settings with which they have some familiarity through their reading or general knowledge. The more diverse the role you are asking someone to play, the more detail concerning the role you will be forced to give. For example, student knowledge of a trade union representative in a collective bargaining role-play is likely to be limited and require far more guidance than if you were to simply ask the student to play the role of a worker. Students also need clear guidance through sharply defined scenarios and roles. 


\subsection{Using scripted role-play}

Each role-play defines a setting and characters (or roles) through which a story will be developed. What happens when the students take on their roles is uncertain. One solution might be to script the role-play in a more formal and ordered way. It is possible, for example, to specify who speaks when, and identify the ideas, arguments and information that will be conveyed in each speech, without providing the exact words of each speech. The task for each student is to articulate the ideas, information and argument in a way that they feel is consistent with the role. Within such a framework the tutor maintains strong control over the focus of the role-play, while at the same time allowing the student to explore the role through their control over the exact language of the speech. According to Alden (2000), 'The benefit of this form of role play is that it gives scope for students to reflect on their learning, while giving the instructor security from the fear that the activity would "get out of hand" and wander from the desired focus of the role play' (p. 128). 


\title{
6 New technology and SGRP
}

\author{
'Technology alone will not provide an adequate framework for innovation. It might be \\ described as a missile looking for a target.'
}

Freeman and Capper, 1998, p. 2

With the development of conferencing systems and Virtual Learning Environments such as Blackboard and Web CT, the opportunity to use such technology to aid teaching and learning is growing. The conferencing systems, e-mail and the internet are generating new possibilities for the design and use of SGRP (Freeman and Capper, 1998; Ip et al., 2001). As yet, online technology has generated less innovation in simulations and games than in role-play. Whilst there are a number of simulations (e.g. the Virtual Economy) and games currently available via the internet, this mode of access does not affect the dynamic of their use (unless access to the internet is lost part way through a teaching session). In role-play, however, the internet does change the nature of students' interaction.

The Web houses the virtual space for the role-play, enables communication and collaboration among students, and between the students and the lecturers. The Web also enables access to 'just-in-time' resources by making available to students resources (such as up-to-date news from electronic newspapers and web-sites etc.), from all over the world as and when they need them. Without this capability the content of the role-play would be significantly weaker.

Ip et al., 2001

Freeman and Capper (1998) suggest that, as well as enriching SGRP, technology is likely to improve the learning outcomes from such an approach. For example, they suggest that the value of face-to-face role-play is limited by fear of appearing foolish in front of peers. In addition, real-time role-play might require the individual or group in role to respond to a situation or question immediately. Under such pressures, answers may be ill conceived or incorrect. With online technology it is possible to minimise the impact of such conditions. Online discussions via e-mail groups and 'chat rooms' can provide anonymity (as users do not need to use their real name) and time for greater reflection. Freeman and Capper conclude that in their experience online role-play helped students to develop more and better ideas than face-to-face role-play.

Online role-play seems likely to improve information and communications technology skills at the expense of social skills relevant to face-to face interaction. There will also be more emphasis on written communication and less on oral communication. If students participate anonymously, the scope for developing a learning community is also diminished. E-mail and Web-based communication might also fail to create a learning community. Consequently, it might be best to use online role-play in conjunction with a face-to-face approach to role-play. 


\section{Conclusions}

This chapter has argued that SGRP have an important role to play in teaching and learning economics and has suggested a number of ways in which lecturers can develop the effectiveness of their use of these resources in teaching. Effective use requires recognition of potential problems and working to overcome these through careful design, preparation and organisation. In economics we are blessed with a discipline that is rich in material suitable for an SGRP teaching strategy. With some investment of time it is possible to extend our repertoire of teaching skills and to engage students more fully in the process of learning.

\section{Where next?}

The richest source of material concerning the use of SGRP in economics can be found in the Journal of Economic Education. Regular articles appear where authors review their experience of using SGRP in their teaching programmes. An extensive bibliography of articles relating to SGRP can be found at http://www.people.virginia.edu/ cah2k/teaching.html. This is Charles Holt's Economics Games page. Charles Holt is a leading US exponent of the use of SGRP in teaching economics.

An extensive and regularly updated review of websites that offer games and simulations can be found at the LTSN Economics website. In many cases, the games and simulations are offered free of change.

\section{Notes}

1 Case study 1 was devised by Mark Sutcliffe and John Sloman.

2 This can be viewed at: http://www.bized.ac.uk/virtual/economy/ve/info/teachersg2.htm.

3 Case study 2 was devised by John Sloman. 


\section{References}

Alden, D. (1999) 'Experience with scripted role-play in environmental economics', Journal of Economic Education, vol. 30, no. 2, pp. 127-32.

Bartlett and Amsler (1979) Bartlett, R. and Amsler, C. (1979) Simulations and economics, Simulations in higher education, ed. Thorson, E. Hicksville, NY.

Davies, P. (1994) 'Learning through computer simulations', Economics and Business Education, vol. 2, no. 1, pp. 30-5.

Francis, P. and Byrne, A. (1999) Use of Role-play Exercises in Teaching Undergraduate Astronomy and Physics, Astronomical Society Australia.

Freeman, M. and Capper, J. (1998) 'An anonymous asynchronous Web-based role-play', at: http://www.ascilite.org.au/conferences/wollongong98/asc98-pdf/freemancapper.

Gremmen, H. and Potters, J. (1997) 'Assessing the efficacy of gaming in economic education', Journal of Economic Education, vol. 28, no. 4, pp. 291-303.

Ip, A., Linser, R. and Naidu, S. (2001) 'Simulated worlds: rapid generation of Web-based roleplay', at: http://ausweb.scu.edu.au/aw01/papers/refereed/ip/paper.html.

Kolb, D. A. and Allen, D. (1984) Experiential Learning: Experience as the Source of Learning and Development, Prentice Hall, Englewood Cliffs, NJ.

Lowry, P. E. (1999) 'Model GATT: a role-playing simulation course', Journal of Economic Education, vol. 30, no. 2, pp. 119-26.

McCormick, B., Vidler, C. and Thomas, L. (1994) Teaching and Learning the New Economics, Heinemann Educational Books, London.

Neral, J. and Ray, M. (1995) 'Experiental learning in the undergraduate classroom: two exercises', Economic Inquiry, vol. 33, January, pp. 170-4.

Oberhofer, T. (1999) 'Role-playing in the history of economic thought', Journal of Economic Education, vol. 30, no. 2, pp. 112-18.

Rodgers Y. (1996) 'A role-playing exercise for development and international economics courses', Journal of Economic Education, vol. 27, no. 3, pp. 217-23. 